\section{Calculating the survival rate and estimated population density of gravid Aedes aegypti (Diptera, Culicidae) in Rio de Janeiro, Brazil}

\author{
Determinação da taxa de sobrevivência e \\ estimativa da densidade populacional de fêmeas \\ grávidas de Aedes aegypti (Diptera, Culicidae) \\ no Rio de Janeiro, Brasil
}

Rafael Maciel-de-Freitas ${ }^{1}$

Álvaro E. Eiras 2

Ricardo Lourenço-de-Oliveira 1

\footnotetext{
1 Instituto Oswaldo Cruz, Fundação Oswaldo Cruz, Rio de Janeiro, Brasil. 2 Instituto de Ciências Biológicas, Universidade Federal de Minas Gerais, Belo Horizonte, Brasil.

Correspondence R. Maciel-de-Freitas Laboratório de Transmissores de Hematozóarios, Instituto Oswaldo Cruz, Fundação Oswaldo Cruz.

Av. Brasil 4365, Pavilhão Carlos Chagas, Rio de Janeiro, $R J$

21040-900, Brasil.

freitas@ioc.fiocruz.br
}

\begin{abstract}
Population size and daily survival rates of disease vectors are important determinants of vectorial capacity. A mark-release-recapture experiment was conducted in a dengue endemic urban neighborhood of Rio de Janeiro, Brazil, to estimate population size, survival rate and vectorial capacity of Aedes aegypti females using back-pack aspirators and gravid sticky traps (MosquiTRAP). Estimations of the gravid female population size were different when using data gathered from just the MosquiTRAP (3,505 individuals) or aspirator $(1,470)$. However Ae. aegypti survival rates and longevity were similar irrespective of the method of capture. Up to $26.3 \%$ of released females would be able to survive for more than 10 days, the length of time of the extrinsic incubation period. Vectorial capacity value ranged between 0.01567 and 0.4215 and the basic reproductive number $\left(R_{0}\right)$ was estimated to be between 0.0695 and 1.88 .
\end{abstract}

Disease Vectors; Mosquito Control; Dengue

\section{Introduction}

Rio de Janeiro registered the highest number of dengue cases in a Brazilian city over the last 20 years. At present, the serotypes DENV 1, 2 and 3 co-circulate in the city of Rio and its greater metropolitan area, which is considered to be one of the country's most important entry and dissemination points for dengue viruses 1,2 .

The dengue vector Aedes aegypti is generally abundant in urban areas of Rio and is highly resistant to insecticides and susceptible to the dengue virus. It generally breeds in large artificial containers, has high daily survival rates, and moves across variable distances depending on the environment and climate, while its populations are highly genetically structured 3,4,5,6,7,8 Differences in the degree of urbanization and in socio-economic status between adjacent blocks mean that Rio de Janeiro is a mosaic in terms of dengue epidemiology, where specific control activities for each area might be required 4,9,10. Variations in the mosquito population size, daily survival rates, biting rates, and the duration of the extrinsic incubation period and/or dengue virus susceptibility within neighborhoods might elicit differential vectorial capacity, and consequently differences in disease transmission dynamics. Indeed, variations in vectorial capacity directly affect the basic reproductive number, $\mathrm{R}_{0}$, i.e. the expected number of hosts that would be infected by a single infectious person who had been in- 
troduced into a native population $11 . \mathrm{A}_{0}$ value greater than one indicates that the number of people infected by the pathogen increases, while if $R_{0}$ is less than one that number declines 12 . Therefore, knowledge concerning vectorial capacity and the basic reproductive number in a dengue endemic area might generate increased awareness about the epidemiology of the disease and also constitute an important tool for developing successful control campaigns.

The aim of this report is to evaluate the vectorial capacity of Ae. aegypti in a suburban neighborhood of Rio de Janeiro, after assessing mosquito population size and daily survival rates by a mark-release-recapture experiment.

\section{Materials and methods}

\section{Study area}

A mark-release-recapture experiment was conducted in the dengue endemic neighborhood of Olaria (22050'45" South; 4315'39" West), a traditional suburban residential area of the city of Rio de Janeiro. In the 2000 census, Olaria had an estimated population of 62,509 inhabitants in an area of around 369ha, with a density of 169.6 habitants/ha 13. Olaria has a large and extensive network of paved streets with low levels of traffic and is crossed by a railway. Water supply and garbage collection services are regular. Houses in Olaria generally have two to four rooms where no more than four or five people live per house, with large and shaded premises. In 2006, 43 dengue fever cases were registered in Olaria; and in 2007,222 cases were reported. One month before starting field collection in Olaria, the premises index (which records the percentage of positive houses) for immature Ae. aegypti was 10.514.

\section{Mosquitoes}

Ae. aegypti used in mark-release-recapture experiments were obtained from a laboratory colony starter from eggs obtained in ovitraps set in Rio de Janeiro city, that are constantly renewed with field collected eggs. Larvae were fed with fish food (TetraMin) and reared according to guidelines found in Consoli \& Lourenço-deOliveira 15. After emergence, females and males were kept together in a cage $(30 \times 30 \times 30 \mathrm{~cm})$ at 25 $\pm 3^{\circ} \mathrm{C}$ and $65 \pm 5 \% \mathrm{RH}$ and provided with a sucrose solution up to a day before the first blood feeding.

\section{Marking, releasing and recapturing}

Two blood meals were offered in subsequent days to Ae. aegypti females who had emerged for 3 to 4 days. Only fully engorged mosquitoes were used in the experiment. Therefore, we expect all released females to be gravid. Sucrose solution was supplied to females up to the day of release.

In November 2006, a total of 1,240 Ae. aegypti females aged 7 to 8 days were marked with fluorescent dust (Day-Glo Color Corp., Cleveland, USA) and released in the morning (between 8 am and 9 am), approximately one hour after dust marking.

Dust marked Ae. aegypti females were captured with the gravid sticky trap (MosquiTRAP, Ecovec Ltda.), a trap that has been show to be effective in attracting and capturing Ae. aegypti gravid females when installed outdoors 16 and CDC backpack aspirators 17. Captures were performed daily and began one day after release. Thirty houses were randomly selected for aspiration, which was carried out for about 20 minutes per property, including the entire premises. One MosquiTRAP was installed in the vicinity of each of the 104 participating premises in Olaria. MosquiTRAPs consist of a black plastic jar with the internal walls covered with a sticky card that glues and holds the attracted mosquitoes. They were baited with $300 \mathrm{ml}$ of tap water and a synthetic oviposition attractant (AtrAedes, Ecovec Ltda.) for Ae. aegypti gravid females. MosquiTRAPs were inspected daily for the presence of dust marked and non-marked mosquitoes. Daily capture stopped when dust marked females were collected by neither the MosquiTRAP nor the aspirator for three consecutive days. All mosquitoes collected in the field were brought to the laboratory to be identified and checked for the presence of fluorescent dust under a UV light.

\section{Population size and ovarian development analysis}

To estimate the population size of Ae. aegypti in Olaria we used the Lincoln index ${ }^{18}$, which can be defined as: $P=\frac{a n-a}{r}$, where $a$ is the number of released females; $n$ is the total number of mosquitoes captured; and $r$ is the number of marked individuals captured. Once released females were added to the natural population, their number needed to be subtracted from the population estimate $(P)$.

Estimations of population size were done with MosquiTRAP, a trap that essentially captures gravid females, and with the aspirator, a non-selective method. 
In order to evaluate the proportion of gravid females in the natural population, all wild $A e$. aegypti females captured in the aspirator had their ovaries dissected and classified according to Christophers 19. Females with ovaries with stages I, I-II, and II were grouped as being at initial stages of development; stages III and IV were grouped as intermediary stages; and stage $V$ was classified as final stage, once females were gravid.

\section{Estimation of daily survival rates}

The probability of daily survival was estimated by using two models: the exponential 20 and nonlinear 21. Only field data were adjusted to models, in relation to the 7-8 days before mosquito release. For survival estimation analysis, collection data were fit according to one of three methods of capture: trapping only with MosquiTRAP, only with aspirator and with MosquiTRAP plus aspirator. Traditionally, the exponential model has been used to describe mortality patterns in mark-release-recapture experiments with Ae. aegypti, despite its two fundamental drawbacks: it assumes a priori that mosquito mortality is age-independent and it does not consider removal of individuals by the capturing methods. The nonlinear model allows for the correction of estimates caused by the removal of individuals 21 and can be written as: $C(t)=N S^{t} c(1-c)^{t-1}$, where $C(t)$ is the number of marked individuals captured on day $t ; c$ is the daily capture probability; and $S$ is daily survival probability. We fit both models to our data, using linear and nonlinear least squares standard procedures available in the software R 2.2.0 (R Development Core Team, http://www.R-proj ect.org). From the lower and upper 95\% limits of the confidence interval for PDS (estimated by the nonlinear model), we derived two quantities: the average life expectancy, defined as 1/-loge PDS 22, and longevity, defined as PDS 10 , where 10 is the duration of the extrinsic incubation period for dengue virus, when more than $76 \%$ of orally experimentally infected mosquitoes have the virus in the salivary glands 23 . Susceptible mosquitoes that survive in the field for 10 or more days after an infected blood meal are expected to live long enough to transmit the dengue virus. Field collections were not performed on the fifth day after release due to intense rainfall.

\section{Vectorial capacity and basic reproductive} number

After estimating the mosquito population density and daily survival rates, estimates were calculated for the vectorial capacity of Ae. aegypti in Olaria during the mark-release-recapture ex- periment. Vectorial capacity can be estimated as $24: V C=\frac{m b c a^{2} P^{n}}{-L n(P)}$, where $m$ is the number of female mosquitos per person, $b$ is the probability that a female mosquito transmits the pathogen to a human host, $c$ is the probability that a mosquito acquires dengue while biting a viremic human host, $a$ is the number of bites per human per day, $P$ is the mosquito's probability of daily survival, $n$ is the duration of the extrinsic incubation period and $P n$ is the probability of a female mosquito surviving the extrinsic incubation period.

The human population on the 134 inspected premises (418 persons) was correlated with the mosquito population size estimation observed in this report. The probability of an infectious mosquito transmitting dengue was fixed at 0.9015 . Since the probability that a mosquito acquires dengue is influenced by virus titer, we simulated vectorial capacity using three probability values for $c$ : $0.30,0.45$ and 0.55 , with virus titer ranging between $10^{5}$ and $106\left(\mathrm{MID}_{50}\right) / \mathrm{ml} 25,26$. The duration of the extrinsic incubation period would be set at 10 days 23 . Mosquito bites per day were set at 327 , and since $90 \%$ of feeds are usually taken on humans 28 , the human biting rate per day would be $2.712,25$. In the present report, vector capacity was simulated using the survival rates estimated by captures done with MosquiTRAP and aspirator.

The basic reproductive number $\left(\mathrm{R}_{0}\right)$ was calculated as follow 11: $R_{0}=\frac{V C}{r}$, where $V C$ is the vectorial capacity and $r$ is the recovery rate (which we set at 5 days for dengue).

\section{Ethical considerations}

Mark-release-recapture experiment protocols were submitted to and approved by the Fundação Oswaldo Cruz Ethical Committee (CEP/ FIOCRUZ protocol no. 11591-2005). CEP/ FIOCRUZ allowed mark, release and recapture experiments with Ae. aegypti females without cut proboscis as in Honório 29, since this amputation might influence female host-seeking behavior and consequently dispersal patterns and survival rates. As a counterpart, we committed ourselves to suspend mosquito release if any dengue case was registered in the study area before or even during the experiment.

\section{Results}

\section{Recapture rates}

A total of 174 dust-marked Ae. aegypti females were captured by MosquiTRAP and aspirator, 
representing a recapture rate of $14.03 \%$ (Table 1). MosquiTRAP and aspirator caught dust-marked Ae. aegypti females 10 and 8 days after release, respectively. The capturing lasted for 13 days.

\section{Population size and ovarian development analysis}

Considering only data gathering with captures from MosquiTRAP, the Lincoln index estimated the population size in Olaria to be 3,505 gravid females. Meanwhile, data from collections using only the aspirator estimated the number of females to be 4,828 . Since the aspirator is an active and non-selective collection method, i.e., it captures females at all physiological stages, the proportion of gravid females in the population needed to be defined. From the 183 non-marked females collected by the aspirator, the ovaries of 174 were dissected $(95.08 \%)$. Despite the variation within groups per day (Figure 1), gravid females were overall $30.45 \%$ of females captured by the aspirator. Therefore, the aspirator estimated the number of gravid females in the population to be 1,470 .

\section{Daily survival rates and longevity estimates}

The nonlinear model provided higher estimates of daily survival than the exponential method

\section{Figure 1}

Recapture curve and points of dust marked Aedes aegypti females released in Olaria, Rio de Janeiro, Brazil, and captured by MosquiTRAP alone.

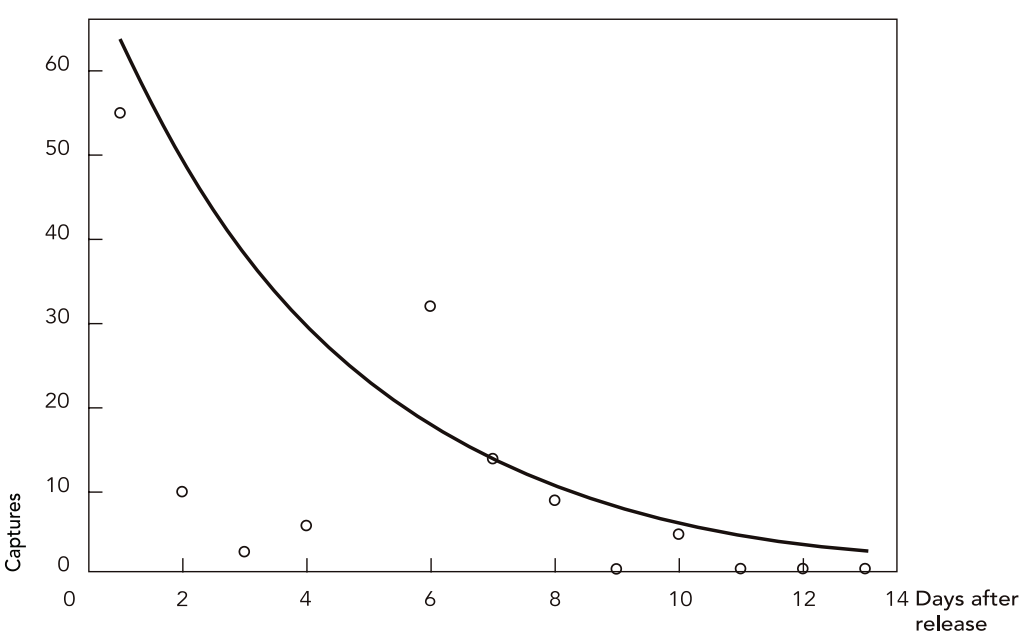

Note: intense rainfall on day 5 after release made field collection impractical.
(Table 2). The low goodness-of-fit, measured as $\mathrm{R}^{2}=0.475$, when data from MosquiTRAP was analyzed, indicated a low fit to the data and promoted high amplitude in the interval of survival (Table 2), which indicated that between $4.23 \%$ and $26.3 \%$ females would be alive 10 days after release and then, able to transmit the dengue virus. With the use of the MosquiTRAP alone, the average life expectancy in the field varied from 3.16 to 7.48 days. When data from the aspirator and MosquiTRAP plus aspirator were analyzed, high goodness-of-fit and low interval of survivorship and average life expectancy values were observed (Table 2). The use of aspiration increased the fit to the data (Table 2).

\section{Vectorial capacity and basic reproductive number estimations}

The vectorial capacity values ranged between 0.0157 and 0.4215 . The lowest value was observed when a daily survival rate of 0.715 and a probability of mosquito infection of 0.30 were used. Meanwhile, the highest value was obtained when vectorial capacity was simulated using a daily survival rate of 0.844 and a probability of mosquito infection of 0.55 . Remarkably, the higher vectorial capacity value was almost 27 times higher than the lowest value.

Using the two vectorial capacity values obtained, the basic reproductive number ranged between 0.0695 and 1.88. Thus, if we consider the lowest value for $\mathrm{R}_{0}$, disease transmission declines. On the other hand the highest value of $\mathrm{R}_{0}$ indicates that the number of people infected by the virus increases.

\section{Discussion}

This report provided an estimate of population size and daily survival rate of Ae. aegypti females in a dengue endemic neighborhood of Rio de Janeiro by conducting a mark-release-recapture experiment using two collection methods. Evaluations of vector population size and survival rates in field conditions are critical for estimating the rate of contact between vectors and hosts, which is a substantial parameter for modeling disease transmission. Unfortunately, estimation of vectorial capacity might be biased since some biological aspects relating to Ae. aegypti females, such as the number of bites per human per day and the duration of the extrinsic incubation period have not been estimated in Rio de Janeiro mosquito populations, with the particular climatic, socio-economic and host herd immunity status characteristics. 
Number of dust and non-marked females captured with the MosquiTRAP and the aspirator in a mark-release-recapture experiment conducted in Olaria, Rio de Janeiro, Brazil.

\begin{tabular}{|c|c|c|c|c|}
\hline \multirow[t]{2}{*}{ Days after release } & \multicolumn{2}{|c|}{ MosquiTRAP } & \multicolumn{2}{|c|}{ Aspirator } \\
\hline & Dust-marked females & Non-marked females & Dust-marked females & Non-marked females \\
\hline 1 & 54 & 53 & 16 & 28 \\
\hline 2 & 9 & 14 & 10 & 13 \\
\hline 3 & 2 & 15 & 4 & 26 \\
\hline 4 & 5 & 3 & 8 & 4 \\
\hline 6 & 31 & 71 & 3 & 11 \\
\hline 7 & 13 & 21 & 3 & 16 \\
\hline 8 & 8 & 28 & 3 & 19 \\
\hline 9 & 1 & 16 & 0 & 3 \\
\hline 10 & 4 & 23 & 0 & 14 \\
\hline 11 & 0 & 15 & 0 & 8 \\
\hline 12 & 0 & 68 & 0 & 21 \\
\hline 13 & 0 & 32 & 0 & 20 \\
\hline Total & 127 & 359 & 47 & 183 \\
\hline
\end{tabular}

Note: there was no collection on day 5 after release due to intense rainfall. A total of 1,240 gravid females were released.

Components of survival analysis of dust-marked Aedes aegypti females released in Olaria, Rio de Janeiro, Brazil, and captured by MosquiTRAP only, aspirator only and by both MosquiTRAP and aspirator.

\begin{tabular}{lccc}
\hline & MosquiTRAP & Aspirator & MosquiTRAP + Aspirator \\
\hline Number of released females & 1,240 & 1,240 & 1,240 \\
Recapture rate (\%) & 10.24 & 3.14 & 13.38 \\
Survival by exponential method & 0.776 & 0.758 & 0.737 \\
R2 * & 0.475 & 0.858 & 0.686 \\
Survival by nonlinear method & 0.795 & 0.771 & 0.773 \\
Interval of survivorship ** & $0.729-0.875$ & $0.74-0.80$ & $0.715-0.844$ \\
Daily recapture rate (\%) & 2.36 & 1.61 & 4.57 \\
Interval of average life expectancy (days) ** & $3.16-7.48$ & $3.32-4.48$ & $2.98-5.89$ \\
\hline
\end{tabular}

* Coefficient of determination;

** Calculated with the $95 \%$ confidence interval provided by the Buonaccorsi nonlinear method.

The recapture rate observed in the neighborhood of Olaria was in accordance with several other mark-release-recapture experiments conducted in Rio de Janeiro 7,30. Collections were performed by means of the daily aspiration of 30 houses and the inspection of 104 MosquiTRAPs. Since released females were gravid, recapture efficiency of MosquiTRAP might have been overestimated, especially on days following release.

The estimate of the Ae. aegypti population size presented different values if data on aspiration or MosquiTRAP were analyzed. This out- come was due to trap specificity, which may result in overestimations of gravid mosquito population size in Olaria during the mark-release-recapture experiment. However, values were high, suggesting the possibility of intense dengue transmission in Olaria despite the mosquito capturing method.

The daily survival rate was also in accordance with a mark-release-recapture experiment conducted in two distinct neighbors of Rio de Janeiro 7. Calculated average life expectancy of $A e$. aegypti in November in Olaria was low for den- 
gue transmission. Theoretically, females should have a lifespan of around 10 days (2 days of nonfeeding and 8-10 days for virus replication) to became an effective dengue vector 23,31 . In Rio de Janeiro, the number of dengue cases has a seasonal trend, with lower dengue transmission in the period between July and November 32 . Possibly, the low lifespan of Ae. aegypti females in November in Olaria is related to the low number of dengue cases during the inter epidemic period. Since average life expectancy is a single value of a distribution, we hypothesize that dengue transmission is possibly due to a few long living females 7 .

Since MosquiTRAP preferentially captures gravid females 16 , this trap possibly caught released dust marked Ae. aegypti females immediately after release. Females of different physiological age might be captured more intensely by the aspirator than by MosquiTRAP 33. This hypothesis is reinforced when Table 1 and Figure 1 are analyzed. The peaks of capturing roughly coincided with the average length of a gonotrophic cycle of Ae. aegypti females, i.e., around 3-4 days 34 . No field collection was performed

\section{Resumo}

O tamanho populacional e a taxa de sobrevivência de vetores de doenças são importantes componentes da capacidade vetorial. Um experimento de marcaçãosoltura-recaptura foi conduzido numa área urbana endêmica de dengue no Rio de Janeiro, Brasil, para estimar o tamanho populacional, taxa de sobrevivência diária e capacidade vetorial de fêmeas de Aedes aegypti; para tal, usaram-se aspirador costal e armadilha para fêmeas grávidas de Ae. aegypti (MosquiTRAP). Estimativas do tamanho populacional de fêmeas grávidas foram diferentes quando foram analisados dados coletados apenas na MosquiTRAP (3.505 indivíduos) e aspiradores (1.470). Por outro lado, taxas de sobrevivência e longevidade de Ae. aegypti foram semelhantes independentemente do método de captura empregado. Até $26,3 \%$ das fêmeas seriam capazes de sobreviver mais do que dez dias, tempo equivalente à duração do período de incubação extrínseco. O cálculo da capacidade vetorial revelou valores entre 0,01567 e 0,4215, e o número básico de reprodução foi estimado entre 0,0695 e 1,88

Vetores de Doenças; Controle de Mosquitos; Dengue on day 5 after release due to intense rainfall in Olaria. Thus, the number of mosquitoes counted in MosquitraPs on day 6 is the sum of the individuals captured on the $5^{\text {th }}$ and $6^{\text {th }}$ days. If we split the number of dust marked mosquitoes captured on day $6(n=31)$, we would still have a peak of marked females between the $5^{\text {th }}$ and $6^{\text {th }}$ days, although it is not a prominent one.

According to a mathematical model of dengue transmission developed by Luz et al. 9, the two most important parameters in vectorial capacity estimations are daily survival rate and the duration of the extrinsic incubation period. Indeed, when vectorial capacity was simulated with the higher survival value observed $(\mathrm{S}=$ 0.844 ), a result 26 times higher than the simulation with the lowest survival rate $(S=0.715)$ was observed, despite the concomitant variation in the probability of a mosquito acquiring the dengue virus. Increases in vectorial capacity have the consequent outcome of amplifying $\mathrm{R}_{0}$, the basic reproductive number. $A R_{0}$ of 0.0695 suggest the number of people infected by the dengue virus in Olaria is in decline. Alternatively, a $\mathrm{R}_{0}$ of 1.88 suggest intense dengue transmission 11,12.

\section{Contributors}

R. Maciel-de-Freitas was responsible for the field work. R. Maciel-de-Freitas, A. E. Eiras and R. Lourenço-deOliveira were responsible for designing the experiment and writing the manuscript.

\section{Acknowledgments}

We would like to thank Roberto C. Peres and Reginaldo L. S. Rego for field collections, Mauro Brandolini, Fábio Castello and Fernando Alves for technical support and Cristiane Vicente and Marcelo Gomes for laboratory assistance. Ecovec is also acknowledged for providing MosquiTRAP and AtrAedes. Financial support: Conselho Nacional de Desenvolvimento Científico e Tecnológico. 


\section{References}

1. De-Simone TS, Nogueira RMR, Araújo ESM, Guimarães FR, Santos FB, Schatzmayr HG, et al. Dengue virus surveillance: the co-circulation of DENV-1, DENV-2 and DENV-3 in the State of Rio de Janeiro, Brazil. Trans R Soc Trop Med Hyg 2004; 98:553-62.

2. Lourenço-de-Oliveira R, Vazeille M, Fillips AMB, Failloux AB. Aedes aegypti in Brazil: genetically differentiated populations with high susceptibility to dengue and yellow fever viruses. Trans R Soc Trop Med Hyg 2004; 98:43-54.

3. Braks MAH, Honório NA, Lourenço-de-Oliveira R, Juliano SA, Lounibos LP. Convergent habitat segregation of Aedes aegypti and Aedes albopictus (Diptera: Culicidae) in southeastern Brazil and Florida. J Med Entomol 2003; 40:785-94.

4. Costa-Ribeiro MCV, Lourenço-de-Oliveira R, Failloux AB. Higher genetic variation estimated by microsatellites compared to isoenzyme markers in Aedes aegypti from Rio de Janeiro. Mem Inst Oswaldo Cruz 2006; 101:917-21.

5. Cunha SP, Alves JRC, Lima MM, Duarte JR, Barros LCV, Silva JL, et al. Presença de Aedes aegypti em Bromeliaceae e depósitos com plantas no município do Rio de Janeiro. Rev Saúde Pública 2002; 36:244-5.

6. Maciel-de-Freitas R, Brocki-Neto RW, Gonçalves JM, Codeço CT, Lourenço-de-Oliveira R. Movement of dengue vectors between human modified environment and an urban forest in Rio de Janeiro. J Med Entomol 2006; 43:1112-20.

7. Maciel-de-Freitas R, Codeço CT, Lourenço-deOliveira R. Daily survival rates and dispersal of $\mathrm{Ae}$ des aegypti females in Rio de Janeiro, Brazil. Am J Trop Med Hyg 2007; 76:659-65.

8. Montella IR, Martins AJ, Viana-Medeiros PF, Lima JBP, Braga IA, Valle D. Insecticide resistance mechanisms of Brazilian Aedes aegypti populations from 2001 to 2004. Am J Trop Med Hyg 2007; 77:467-77.

9. Luz PM, Codeço CT, Massad E, Struchiner CJ. Uncertainties regarding dengue modeling in Rio de Janeiro, Brazil. Mem Inst Oswaldo Cruz 2003; 98:871-8.

10. Maciel-de-Freitas R, Marques WA, Peres RC, Cunha SP, Lourenço-de-Oliveira R. Variation in Aedes aegypti (Diptera: Culicidae) container productivity in a slum and a suburban district of Rio de Janeiro during dry and wet seasons. Mem Inst Oswaldo Cruz 2007; 102:489-96.

11. Wernsdofer WH, McGregor I. Malaria: principles and practice of malariology. Edinburgh: Churchill Livingstone; 1989.

12. Smith DL, McKenzie FE, Snow RW, Hay SI. Revisiting the basic reproductive number for malaria and its implications for malaria control. PLoS Biol 2007; 5:e42.

13. Armazém de Dados da Prefeitura do Rio de Janeiro. Informações sobre a cidade do Rio de Janeiro. http://www.armazemdedados.rio.rj.gov.br (accessed on $31 / \mathrm{Jan} / 2008$ ).
14. Secretaria Municipal de Saúde do Rio de Janeiro. Casos de incidência de dengue por bairro e mês no Município do Rio de Janeiro - 2007. http:/ /www. saude.rio.rj.gov.br/saude/pubsms/media/tab_ incidengue2007.htm (accessed on 28/Abr/2008).

15. Consoli RAGB, Lourenço-de-Oliveira R. Principais mosquitos de importância sanitária do Brasil. Rio de Janeiro: Editora Fiocruz; 1994.

16. Fávaro EA, Dibo MR, Mondini A, Ferreira AC, Barbosa AAC, Eiras AE, et al. Physiological state of Aedes (Stegomyia) aegypti mosquitoes captured with MosquiTRAPs in Mirassol, São Paulo, Brazil. J Vector Ecol 2006; 31:285-91.

17. Clark GG, Seda H, Gubler DJ. Use of the "CDC backpack aspirator" for surveillance of Aedes aegypti in San Juan, Puerto Rico. J Am Mosq Control Assoc 1994; 10:119-24.

18. Service MW. Mosquito ecology: field sampling methods. London: Chapman \& Hall; 1993.

19. Christophers SR. The development of the egg follicle in anophelines. Paludism 1911; 2:73-8.

20. Gillies MT. Studies on the dispersion and survival of Anopheles gambiae Giles in East Africa, by means of marking and releasing experiments. Bull Entomol Res 1961; 52:99-127.

21. Buonaccorsi JP, Harrington LC, Edman JD. Estimation and comparison of mosquito survival rates with release-recapture-removal data. J Med Entomol 2003; 40:6-17.

22. Niebylski ML, Craig GB. Dispersal and survival of Aedes albopictus at a scrap tire yard in Missouri. J Am Mosq Control Assoc 1994; 10:339-43.

23. Salazar MI, Richardson JH, Sánchez-Vargas I, Olson KE, Beaty BJ. Dengue virus type 2: replication and tropisms in orally infected Aedes aegypti mosquitoes. BMC Microbiol 2007; 7:9.

24. Garrett-Jones C. Prognosis for interruption of malaria transmission through assessment of the mosquito's vectorial capacity. Nature 1964; 204:792-3.

25. Focks DA, Daniels E, Haile DG, Keesling JE. A simulation model of the epidemiology of urban dengue fever: literature analysis, model development, preliminary validation, and samples of simulation results. Am J Trop Med Hyg 1995; 53:489-506.

26. Jetten TH, Focks DA. Potential changes in the distribution of dengue transmission under climate warming. Am J Trop Med Hyg 1997; 57:285-97.

27. Focks DA, Haile DG, Daniels E, Mount GA. Dynamic life table model for Aedes aegypti (Diptera: Culicidae): analysis of the literature and model development. J Med Entomol 1993; 30:1003-17.

28. Scott TW, Chow E, Strickman D, Kittayapong P, Wirtz RA, Lorenz LH, et al. Blood-feeding patterns of Aedes aegypti (Diptera: Culicidae) collected in a rural Thai village. J Med Entomol 1993; 30:922-7.

29. Honório NA, Silva WC, Leite PJ, Gonçalves JM, Lounibos LP, Lourenço-de-Oliveira R. Dispersal of Aedes aegypti and Aedes albopictus (Diptera: $\mathrm{Cu}-$ licidae) in an urban endemic dengue area in the State of Rio de Janeiro, Brazil. Mem Inst Oswaldo Cruz 2003; 98:191-8. 
30. Maciel-de-Freitas R, Eiras AE, Lourenço-de-Oliveira R. Field evaluation of effectiveness of the BGSentinel, a new trap for capturing adult Aedes aegypti (Diptera: Culicidae). Mem Inst Oswaldo Cruz 2006; 101:321-5.

31. Kuno G. Review of the factors modulating dengue transmission. Epidemiol Rev 1995; 17:321-35.

32. Nogueira RMR, Miagostovich MP, Schatzmayr HG, Santos FB, Araújo ESM, Filippis AMB, et al. Dengue in the State of Rio de Janeiro, Brazil, 1986-1998. Mem Inst Oswaldo Cruz 1999; 94:297-304.
33. Maciel-de-Freitas R, Peres RC, Alves F, Brandolini MB. Mosquito traps designed to capture Aedes aegypti (Diptera:Culicidae) females: preliminary comparison of Adultrap, MosquiTRAP and backpack aspirator efficiency in a dengue endemic area of Brazil. Mem Inst Oswaldo Cruz 2008; 103:602-5

34. Pant CP, Yasuno M. Field studies on the gonotrophic cycle of Aedes aegypti in Bangkok, Thailand. J Med Entomol 1973; 10:219-223.

Submitted on $31 /$ Oct $/ 2007$

Final version resubmitted on 30/Jan/2008

Approved on 31/Jan/2008 